\title{
2006-2385: VERTICAL MENTORING: CLOSING THE LOOP IN DESIGN
}

\section{Glen Livesay, Rose-Hulman Institute of Technology}

GLEN A. LIVESAY is an Associate Professor of Applied Biology and Biomedical Engineering. He teaches undergraduate and graduate courses on biomechanics, capstone design, experimental design and statistics and data analysis, and experimental biomechanical testing of soft tissues.

\section{Renee Rogge, Rose-Hulman Institute of Technology}

RENEE D. ROGGE is an Assistant Professor of Applied Biology and Biomedical Engineering. Her teaching interests include orthopaedic and sports biomechanics, biomaterials, capstone design, and introductory level mechanics courses. 


\title{
Vertical Mentoring: Closing the Loop in Design
}

\begin{abstract}
To help students 'close the loop in design' - that is, appreciate the importance and depth of their design knowledge through a specific demonstration of this ability beyond their capstone design project - we have implemented a vertical mentoring scheme in biomedical engineering design. Biomedical engineering seniors in the fourth quarter of the design sequence serve as design mentors to teams of juniors beginning their first quarter of design.

In the junior-level course, student teams work on a smaller, common design project to 'practice' a complete iteration of the design process before they tackle larger, more open-ended design projects the following term. The seniors, in contrast, are nearing completion of their capstone design projects, conducting product testing vs. design specifications, final documentation, and their final public presentation. In addition to the technical aspects of design, the learning objectives of this senior course include supporting and mentoring the juniors as they are introduced to the engineering design methodology. The seniors role play (in the lecture portion of their course) to learn to guide junior design teams; not telling the teams what to do, but asking questions to uncover potential problems they may encounter.

The most notable outcome from the vertical mentoring experience for the seniors is not that they are helping a junior design team, rather that they realize that they are capable of helping. The seniors are viewed (quite correctly, it turns out) by the Juniors as 'design experts' and this reinforces the idea that engineering design is a process, since the seniors do not have any more direct experience with the specific product than the juniors. The major benefit perceived by the Juniors - beyond the guidance they receive on their projects - is the immediate vocational relevance that is provided to the design sequence. The seniors represent where the juniors will 'be' next year at this time, and since the seniors "know what they are doing" these design courses must be important and/or useful.
\end{abstract}

\section{Introduction}

Just as many times it is not possible to 'see the forest for the trees', it is also true that often the heights to which one has climbed cannot be appreciated until one has a clear (over)view of the surrounding terrain. With this in mind, we developed a four-quarter sequence in biomedical engineering design that features an extended vertical mentoring interaction between seniors in the final quarter of their capstone experience and junior design teams just beginning the design process.

The main intent of vertical mentoring - that is, bringing students of different cohorts together is to enable more senior (usually upperclassmen) students to guide and advise their more junior classmates. It depends on the specific situation as to whether the mentoring is specific (the Seniors advise) or 'by example' (the Seniors are leading the overall task, and Juniors, etc. learn by watching the Seniors, and undertake simpler tasks under the direction of the Seniors). Both of these are valuable approaches and serve potentially different roles. Leading by example is an 
important part of professional development and movement from the role of a student into the role of a professional. Being able to seek the specific advice/wisdom of a mentor is important for the mentee, and learning to guide/assist a junior colleague without specifically 'directing them' is also an important professional skill for an engineer. In some ways, this is one of the hallmarks of an engineer who is ready to make the transition from the academic setting out into the real world (of industry, or other situations) ${ }^{[4]}$. Recently, Rowley ${ }^{[2]}$ has reported success using biomedical engineering seniors as mentors for freshman design, from the freshman, senior, and instructor perspectives.

Our overall rationale for using seniors as 'design mentors' for the juniors involved such factors as providing immediate vocational relevance to the juniors ("that's me next year"), the potential for conveying 'design wisdom and truth' from class to class, and also to provide the juniors with specific examples of students who have undertaken the capstone design project and have succeeded.

\section{Methods}

Students enrolled in the fourth course of the biomedical engineering design sequence were used to mentor students in the first course of the design sequence.

Below are the formal course titles and their placement in the BE curriculum at Rose-Hulman. The design sequence is a total of four quarters long, comprising 10 credit hours (quarter system). The ability to utilize BE seniors to mentor juniors in the Spring quarter is embedded in the overall structure of the sequence. A brief description of the courses in the design sequence is provided to make the use of the vertical mentoring scheme clearer:

\begin{tabular}{|l|c|c|}
\hline Course Title & Time in BE Curriculum & Credit Hours \\
\hline Principles of Biomedical Engineering Design & Spring quarter, Junior & 1R-3L-2C \\
\hline Biomedical Engineering Design I & Fall quarter, Senior & 3R-3L-4C \\
\hline Biomedical Engineering Design II & Winter quarter, Senior & 2R-6L-4C \\
\hline Biomedical Engineering Design III & Spring quarter, Senior & 1R-3L-2C \\
\hline \multicolumn{2}{|r|}{ Note: ' $R$ ' $=$ lecture hours, ' $L$ ' = laboratory hours, 'C' = overall course credit. }
\end{tabular}

\section{Principles of Biomedical Engineering Design}

This is the first course in the sequence, and students learn the design process through the completion of team projects. The quarter involves a complete iteration of the design process on a real device, from assessing needs, generating multiple feasible solutions, ranking these based on the merit of the solutions, selecting the best design, constructing, and evaluating performance relative to initial design specifications. Teams undertake a common project - in terms of client needs - although design products to meet these needs may vary.

\section{Biomedical Engineering Design I \& II}

During these two quarters, seniors undertake and construct their capstone design project working on a relevant problem in biomedical engineering. This begins from the development of the design problem from a set of (real) client needs, establishing specifications, planning the project, scheduling and efficient use of resources, examining ethics and safety in engineering design, and 
working within explicit (or implicit) constraints, such as social, fiscal, manufacturing, etc. The Fall quarter culminates with the presentation of the preliminary proposal for the capstone design project in biomedical engineering. In the Winter term, student teams implement their design plan. This includes development of a test plan, modifications to the design project as needed, and assessment of design performance relative to initial specifications. This term concludes with the submission of the final design document.

\section{Biomedical Engineering Design III}

The biomedical engineering design sequence culminates in the formal oral presentation of the capstone design project in this term. Throughout the remainder of the course, students are introduced to additional skills necessary for professional practice in biomedical engineering, including more detailed project management, quantitative review of critical design decisions, etc. Students spend a sizable portion of this term also learning about what makes a good mentor, the various student (and person) types and their potential impact on team interactions/function, models of intellectual development, role-playing as mentors with peers, and mentoring junior design teams.

\section{Mentoring Set-up}

The vertical mentoring was conducted over a six-week period in the Spring quarter 2004/05, with 'official' (in-class) interactions occurring during a scheduled, common three-hour lab period. The first meeting between the junior teams and their senior mentors was conducted during a lab prior to the juniors beginning their design projects. In this lab, juniors were working with the basics of design terminology, developing problem statements, determining if solutions were feasible, developing and using merit criteria, and selecting the best design (for a smaller test case) from multiple alternatives. Senior mentors worked with the junior teams as they undertook the day's task, reinforcing definitions/distinctions the juniors had learned in lecture, providing additional explanations, and answering questions as needed. This first-day interaction between mentors and junior teams was specifically set-up so that the first 'official' interaction between the mentors and the design teams would not coincide with the added stress of learning about the 'real project' the juniors were to undertake.

While seniors were provided instruction concerning mentoring and team interaction, they were not coached in regards to the specifics of the design project the juniors were completing in any way. The seniors role play (in the lecture portion of their course) to learn to guide junior design teams; not telling the teams what to do, but asking questions to uncover potential problems they may encounter. Subsequent meetings between senior mentors and their junior teams were conducted during the weekly lab periods (and out of class on an ad-hoc basis) after the juniors had begun their design projects. This enabled the first 'project' interaction between the mentors and teams to be to when the junior teams explained their understanding of the project and its overall goals to the mentors. Junior teams were allowed to request specific seniors to serve as mentors, although actual assignment was performed by the design sequence instructors.

\section{Feedback on Mentoring and the Juniors' Design Process}

Formative feedback on the usage of the senior mentors and their performance was obtained from the juniors at the midpoint of the quarter, and summative feedback at the conclusion of the design project. 
Each week after working with the junior teams, the seniors completed brief, written assignments in which they reviewed their interactions with the junior design teams ("What sort of questions are being asked, and what assistance are you providing?") and also speculated as to what they thought were the underlying reasons for the questions ("What aspects of the design process appear to be unclear, or present challenges?"). Seniors also completed assignments in which they were asked to reflect on their own experiences in design (cast largely in terms of questions regarding the junior teams), as a way to guide them through a process of 'closing the loop' on their own capstone design experience. Summative feedback was obtained from the seniors at the end of the term, both on the mentoring process and interactions, as well as the overall biomedical engineering design sequence.

\section{Results/Observations}

Since the vertical mentoring scheme was run with our first graduating class of biomedical engineers (mentoring our second graduating class), and was required for all BE seniors, there is not a control group available or a longitudinal expectation with which to compare the impact of this approach. With that caveat, summative feedback from the junior design teams was uniformly positive, and indicated that they felt the senior mentors 'really helped them'. Written comments regarding the 'help' provided revealed that the seniors were functioning as mentors (and not doing the project for the juniors). The very presence of the seniors as mentors ("just in case") increased the confidence of the juniors to tackle their project. Seniors were noted for how "knowledgeable and non-flustered" they were when working with design, and a great many positive comments regarding the mentoring scheme also appeared in the course evaluations collected by the Dean's office at the end of the term.

In addition to mentoring the juniors, the weekly senior feedback on the interactions with the junior teams also provided valuable information regarding the topics in design that the instructors needed to reinforce (e.g. merit vs. feasibility criteria). Seniors did vary somewhat in the amount of detail they provided regarding interactions with the junior design teams, but experiences were relatively similar and positive across teams. Summative feedback from the seniors indicated that they generally enjoyed the mentoring, that they felt 'prepared' to assist with design, and that they were glad to help the juniors. Moreover, the majority of them wished that they had had mentors when they were juniors, but being the first graduating class of biomedical engineers here, there were no seniors ahead of them.

The summative, reflective feedback provided by the seniors was extensive and was collected electronically by the instructors. The major observation from this data was that the seniors all felt that they had gained important skills and perspective in which made them more confident in their ability to undertake a design project through the process of mentoring a junior design team. While specific opinions regarding the seniors felt about mentoring ranged from 'I enjoyed it' to 'it was fantastic!', every student reported some overall feeling that they had learned something or been validated on some level (thanks to mentoring).

The low end (still very positive for 'closing the loop'): 
"I think the in-class time we spent talking to the Juniors was useful to them, and being a mentor is nice because it proves we learned something even if we didn't think we learned anything."

At the top end (a real comment from a real student):

"Taking part in every aspect of the design process is critical to understanding the process and mastering it. By serving as a mentor, you still need to be able to make good design decisions but not be immersed in an individual project. This is important and has really helped my critical thinking"

\section{Discussion}

The vertical mentoring process, although more time-consuming for the instructors to set-up and initiate than a separate pair of design courses, worked extremely well in the first iteration. Once the students understood how things would work - with lecture periods as separate classes of juniors and seniors, and a combined lab period during which the mentoring occurred - the courses (BE 390 and BE 430) ran very smoothly. The fact that juniors would benefit from the extensive design experience of a senior (in a relative sense) was an expected and positive outcome of the vertical mentoring scheme. The seniors were viewed by the juniors as 'design experts' and this reinforces the idea that engineering design is a process - and a process that can be learned - since the seniors had no more direct experience with the specific product than the juniors.

The major planned outcome of this approach was to give the seniors training as team and technical mentors as well as experience guiding a junior team through a complete iteration of the design process. Since design is an inherently iterative process, it was expected that this planned interaction would give the seniors an opportunity to 'close the loop in design' by providing time to reflect on the process from a different perspective. Based on the feedback from the seniors, this outcome was achieved, and there were many comments regarding how interesting it was to look back in on a design team just learning the process. The most notable outcome from the vertical mentoring experience for the seniors, however, appears to be not that they were helping a junior design team, rather that they realized that they were capable of helping. This was not expected, as the seniors, having just completed their capstone design project with a real client immediately prior to mentoring the junior, should certainly have felt qualified to do design, particularly since they have just demonstrated it through the construction of their device (this is, of course, in the opinion of the instructors).

In essence, the summative feedback from the seniors indicated that they had more confidence in their own ability to mentor design teams, and also in their ability to conduct engineering design. It is worth noting, however, that the seniors have already completed their capstone design projects prior to mentoring the juniors, and that there was no new technical design information that the seniors were learning during this quarter. So, is it the process of mentoring a design team that is building this confidence in the seniors' abilities? This seems a strong possibility, in that they are looking back on a design process and can actually see how far they have come since they were juniors. At the same time, it is possible that being closer to graduation inspires this confidence, or just that the passage of time since the conclusion of a major design project makes the full impact of the experience be felt. To assess the learning of the design students who will 
participate in the next iteration of the vertical mentoring scheme beyond their design projects, longitudinal concept mapping ${ }^{[3]}$ (at the conclusion of each of the four quarters in the design sequence) is being implemented. Alternative assessments of students' confidence in their design abilities could also be collected ${ }^{[1]}$. These might enable further determination of the impact of mentoring not only on the ability guide a team and gain a new perspective, but also on the ability of this experience to help students potentially synthesize and organize their design knowledge more effectively for future use.

\section{Conclusions}

The first iteration of the vertical mentoring scheme in the biomedical engineering design sequence was successful, and it is slated to be utilized again in Spring 2005/06. The unexpected benefit of the mentoring scheme - in that seniors perceptions of and confidence in their own ability in engineering design increased through the process of mentoring - is also an important outcome. Additional work to obtain alternative measures of 'design learning, ${ }^{[3]}$ are being implemented to investigate the impact of mentoring design teams on the overall synthesis of design knowledge. Based on our experiences thus far, vertical mentoring of this form provides benefits to both the design mentors (seniors) and the design working groups (the juniors) that far outweigh any extra efforts required to coordinate the two courses.

\section{References}

1. McKenna, A.F. and Hirsch, P.: Evaluating student confidence in engineering design, teamwork, and communication. Proceedings of the American Society for Engineering Education, Session 2630, 2005.

2. Rowley, B.A.: BME senior design and freshman engineering. Proceedings of the American Society for Engineering Education, Session 1109, 2005.

3. Walker, J.T. and King, P.H.: Concept mapping as a form of student assessment and instruction in the domain of bioengineering. Journal of Engineering Education, 92: 167-179, 2003

4 Williams, S.M., Reyer, S.E., and Petersen, O.G.: Senior design as a transition from academia to industry, Proceedings of the American Society for Engineering Education, Session 2425, 2005. 